\title{
EDITORIAL
}

\section{LEPROSY CONTROL IN THE WeST INDIES}

The West Indian Colonies have from the first been regarded by B.E.L.R.A. as specially favourable for the successful application of modern methods of controlling, and eventually stamping out, leprosy. Unfortunately the results of the visits to this area of two former B.E.L.R.A. secretaries, to urge the adoption of these methods, proved very disappointing owing to the fact that few of their recommendations were carried out by the island authorities. This was doubtless partly due to financial stringency, although this has not prevented the successful use of these methods in British Guiana by Dr. F. G. Rose, as recorded in our last issue. The recent visits of Dr. E. Muir to a number of the West Indies Islands and his work and recommendations reported in detail in our present issue are very timely in view of the financial assistance which is likely to be provided in the post-war era by the Colonial Development Fund.

Trinidad has been in the forefront by providing a decade 


\section{IODISED}

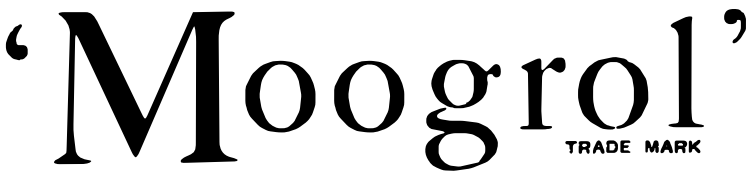

A Mixture of Esters of Acids of the Chaulmoogric Series with 0.5 per cent of Iodine

For the treatment of all forms of leprosy by combined intramuscular and intradermal injection.

The addition of iodine to the esters minimises local irritation and permits systematic infiltration of lepromata.

Bottles of 25 c.c., 100 c.c. and 1 litre

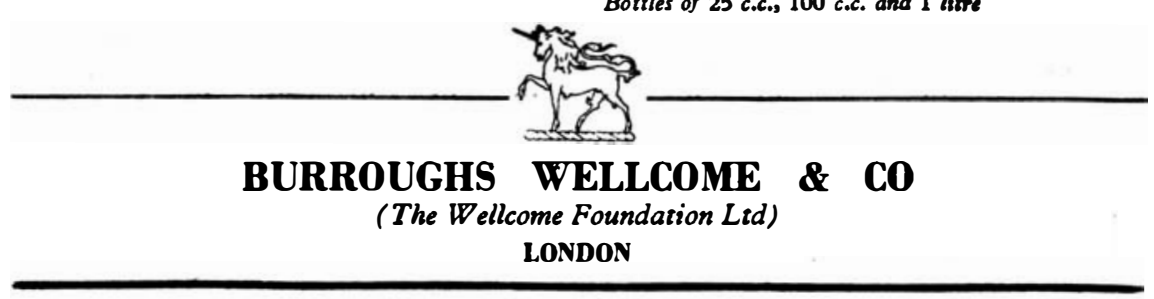

INJECTION

INSTRUMENTS

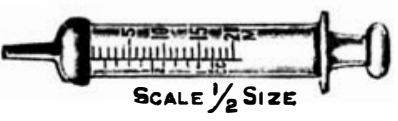

Glascord Syringes complete in case with 2 needles, in following sizes:-

20 min. and 1 c.c. $2 c . c ., 5 c . c$. , 10c.c. and 20c.c.

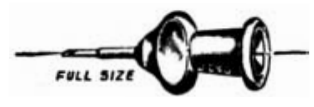

Record Needles for INTRADERMAL INJECTIONS as illustrated, stainless steel.

Sizes 23 and 25 S.W.G.

\section{J. GARDNER \& SON}

\section{Surgical Instrument Makers} to the Edinburgh Royal Infirmary, etc.

\section{FORREST ROAD, EDINBURGH}

Works: 90 CANDLEMAKER ROW, EDINBURGH 
or two ago the Chacachacare I epprosy Island settlement (where Dr. Muir has becn working since the outbreak of the war) in place of an old prison-like asylum in the capital town. Surveys of areas in Trinidad by Dr. Muir have led to the adoption of the long advocated and essential measure of providing weekly hospital and dispensary clinics, where early uninfective cases are treated without segregation, and it is hoped when the surveys are completed to make provision for such economical treatment of all suitable cases.

The report on the large island of Jamaica, on the other hand, shows very little progress in leprosy control since the visit of the writer of this article to the Spanish Town I.eper Asylum almost twenty years ago, except in the recent important provision of nursing sisters. Both overcrowding and the accommodation of early and advanced cases in the same dormitories still persist, and plans for improving matters still. await funds for carrying them out. It is to be hoped that Dr. Muir's advice on these and other matters will receive effective support, for this comparatively large colony should set a good example to other smaller and poorer West Indian Islands, in some of which a beginning has yet to be made in the adoption of modern methods of leprosy control and treatment.

The following recommendations for remedying defects such as those pointed out in Dr. Muir's reports are those suc cessfully adopted in India and also in British Guiana: The ground should be prepared by surveys to ascertain the prevalence of the disease and by propaganda to remove the ignorance that so greatly handicaps progress. Next and most important is the introduction of clinics for early cases and the release of, or the provision of separate accommodation for, advanced uninfective crippled nerve cases, thus enabling all infectives ones to be admitted while still amenable to treatment in a hopeful atmosphere. Periodic examination of all school children should be made to ensure that early cases, and especially infective ones, are detected among contacts. All known contacts and discharged recovered cases should be examined every few months for several years to enable new cases and relapses to be discovered. For this purpose at least one medical officer, and preferably all the health officers, should in turn be given a few months training at either the Trinidad or the British Guiana settlements. When these and the other practical recommendations of Dr. Muir have been systematically carried out for a decade or two the leprosy problem in the West Indies will be well on the way to a successful solution. 